\title{
The antioxidant, aged garlic extract, exerts cytotoxic effects on wild-type and multidrug-resistant human cancer cells by altering mitochondrial permeability
}

\author{
SHINJI OHKUBO ${ }^{1}$, LISA DALLA VIA ${ }^{2}$, SILVIA GRANCARA $^{1}$, YUTA KANAMORI $^{1}$, \\ AÍDA NELLY GARCÍA-ARGÁEZ ${ }^{2}$, GIANLUCA CANETTIERI ${ }^{3}$, PAOLO ARCARI ${ }^{4,5}$, \\ ANTONIO TONINELLO ${ }^{6}$ and ENZO AGOSTINELLI ${ }^{1}$
}

\author{
${ }^{1}$ Department of Biochemical Sciences ‘A. Rossi Fanelli’, Sapienza University of Rome, I-00185 Rome; \\ ${ }^{2}$ Department of Pharmaceutical and Pharmacological Sciences, University of Padua, I-35131 Padua; \\ ${ }^{3}$ Department of Molecular Medicine - Sapienza University of Rome, 00161 Rome; ${ }^{4}$ Department of Molecular Medicine and \\ Medical Biotechnology, University of Naples Federico II, I-80138 Naples; ${ }^{5}$ CEINGE, Advanced Biotechnology Scarl, \\ I-80145 Naples; ${ }^{6}$ Department of Biomedical Sciences, University of Padua, I-35131 Padua, Italy
}

Received March 15, 2018; Accepted May 16, 2018

DOI: $10.3892 /$ ijo.2018.4452

\begin{abstract}
Aged garlic extract (AGE) has been shown to possess therapeutic properties in cancer; however its mechanisms of action are unclear. In this study, we demonstrate by MTT assay that AGE exerts an anti-proliferative effect on a panel of both sensitive and multidrug-resistant (MDR) human cancer cell lines and enhances the effects of hyperthermia $\left(42^{\circ} \mathrm{C}\right)$ on M14 melanoma cells. The evaluation of the mitochondrial activity in whole cancer cells treated with AGE, performed by cytofluorimetric analysis in the presence of the lipophilic cationic fluorochrome JC-1, revealed the occurrence of dose-dependent mitochondrial membrane depolarization. Membrane potential was measured by the $\mathrm{TPP}^{+}$selective electrode. In order to shed
\end{abstract}

Correspondence to: Professor Enzo Agostinelli, Department of Biochemical Sciences 'A. Rossi Fanelli', Sapienza University of Rome, Piazzale Aldo Moro 5, I-00185 Rome, Italy

E-mail: enzo.agostinelli@uniroma1.it

Abbreviations: AGE, aged garlic extract; SAC, S-allylcysteine; SAMC, S-allylmercaptocysteine; ROS, reactive oxygen species; CNS, central nervous system; WT, wild-type; MDR, multidrug-resistant; RLM, rat liver mitochondria; MTT, thiazolyl blue tetrazolium bromide; FBS, fetal bovine serum; JC-1, 5,5',6,6'-tetrachloro-1,1',3,3'-tetraethylimidacarbocyanine iodide; BSA, bovine serum albumin; $\Delta \psi \mathrm{m}$, mitochondrial membrane potential; $\mathrm{TPP}^{+}$, tetraphenylphosphonium; $\Delta \mu_{\mathrm{H}}{ }^{+}$, electrochemical gradient; CsA, cyclosporin A; BKA, bongkrekic acid; ADP, adenosine diphosphate; MPT, mitochondrial permeability transition; RR, ruthenium red; NEM, N-ethylmaleimide; DTE, 1,4-dithioerythritol; PEG, polyethylene glycol; BSAO, bovine serum amine oxidase; AdNT, adenine nucleotide translocase

Key words: aged garlic extract, anti-proliferative activity, cancer cells, mitochondria, mitochondrial permeability transition light on its mechanisms of action, the effects of AGE on isolated rat liver mitochondria were also examined. In this regard, AGE induced a mitochondrial membrane hyperpolarization of approximately $15 \mathrm{mV}$ through a mechanism that was similar to that observed with the ionophores, nigericin or salinomycin, by activating an exchange between endogenous $\mathrm{K}^{+}$with exogenous $\mathrm{H}^{+}$. The prolonged incubation of the mitochondria with AGE induced depolarization and matrix swelling, indicative of mitochondrial permeability transition induction that, however, occurs through a different mechanism from the well-known one. In particular, the transition pore opening induced by AGE was due to the rearrangement of the mitochondrial membranes following the increased activity of the $\mathrm{K}^{+} / \mathrm{H}^{+}$exchanger. On the whole, the findings of this study indicate that AGE exerts cytotoxic effects on cancer cells by altering mitochondrial permeability. In particular, AGE in the mitochondria activates $\mathrm{K}^{+} / \mathrm{H}^{+}$exchanger, causes oxidative stress and induces mitochondrial permeability transition (MPT).

\section{Introduction}

The number of cancer patients worldwide has recently been increasing. The failure of conventional chemotherapy requires new approaches for successful cancer treatment. Considering that patients with gastrointestinal cancer have represented one of the largest segment of the population with cancer, diet is likely to be intimately associated with cancer development. Therefore, diet and nutrition have been considered to play an important role in the pathogenesis of carcinogenesis (1).

Garlic (Allium sativum L.) is a species of the onion family, Alliaceae that has been widely used as a food and also as a folk medicine. A number of epidemiological studies have suggested that garlic is effective in the prevention and treatment of several human diseases with multiple pharmacological functions, such as anticarcinogenic (2), antithrombotic (3), hypolipidemic (4) and hepatoprotective (5) activity. Over the past decades, this herb has been reported to suppress carcinogenesis and 
to inhibit the proliferation of cancer cells (e.g., esophageal, gastric, colorectal, lung, skin and prostate cancer) in vivo and in vitro (6). Several of the beneficial effects of garlic have been demonstrated to be attributed to several bioactive compounds isolated from garlic, including the lipid-soluble allyl sulfur compounds (e.g., diallyl sulfide, diallyl disulfide and diallyl trisulfide) and water-soluble compounds, such as $S$-allyl cysteine (SAC) and $S$-allylmercaptocysteine (SAMC) (7-14).

Aged garlic extract (AGE) has been shown to possess various water-soluble organic sulfur compounds, such as SAC, SAMC and S-1-propenylcysteine by unique manufacturing process (15). AGE possesses greater antioxidant activity than fresh garlic by scavenging reactive oxygen species (ROS), enhancing the activity of cellular antioxidant enzymes (e.g., superoxide dismutase, catalase and glutathione peroxidase), mainly observed following the administration of SAC in vivo (16), and increasing glutathione levels in cells (17-19). Several studies on both animals and humans have shown that AGE contributes to a reduced risk of cancer $(20,21)$, cardiovascular disease (22-24), Alzheimer's disease and other age-related degenerative conditions $(19,25)$. Moreover, the mode of action of AGE in inhibiting the formation of atherosclerosis in apolipoprotein E-knockout mice has been investigated by examining whether AGE suppresses inflammation (26). An interesting investigation was recently performed using SAC. As reported above, $\mathrm{SAC}$ represents one of the active and main constituents of AGE with anti-inflammatory and neuroprotective properties. Therefore, SAC may be considered a potential candidate in the therapy of neuroinflammatory conditions, such as multiple sclerosis, a deleterious autoimmune and demyelinating disorder of the central nervous system (CNS). That study aimed to evaluate whether SAC can improve clinical and neuropathological characteristics of experimental autoimmune encephalomyelitis in C57BL/6 mice (27).

AGE exerts its cancer-inhibitory effects at both the early and late stages by modulating carcinogen metabolism, decreasing carcinogen binding to DNA and scavenging ROS (19). Studies have demonstrated that AGE exerts chemopreventive effects on chemically-induced colon tumors in rats $(28,29)$. In vitro studies have also demonstrated that AGE suppresses DLD-1 human colon cancer cell proliferation, but does not inhibit that of MRC-5 normal fibroblasts (29). The major unique organosulfur compounds in AGE are SAC and SAMC, which are produced during the long-term extraction of garlic $(30,31)$. A number of studies have demonstrated that SAC and SAMC exert effective cell growth inhibitory effects on human colon and breast cancer cells, and suppress cancer risk by altering the biological behaviors of various human tumors, such as prostate, colon and gastric cancers $(7,8,10,13,14)$.

In patients that are diagnosed as suffering from colorectal adenomas, following treatment with high doses of AGE, both the size and the number of colon adenomas were suppressed (29). Thus, these results suggest that AGE may be a potential agent for use in the treatment of cancer.

To further investigate the anti-proliferative activity of AGE, in this study, we examined the effects of AGE on the proliferation of both sensitive [wild-type (WT)] and multidrug-resistant (MDR) human cancer cell lines. This study was performed at 37 and $42^{\circ} \mathrm{C}$. Moreover, we attempted to elucidate its intracellular mechanisms of action, by focusing on mitochondrial activity in whole cancer cells and in isolated rat liver mitochondria (RLM).

Mitochondria, the key bioenergetic intracellular organelles, contain a high number of proteins having ion channel functions. Increasing evidence points to the important contribution of the channels to the regulation of mitochondrial functions. In fact, ion homeostasis imbalance profoundly affects energy transduction processes, ROS production and mitochondrial integrity. Given the central role of the mitochondria in apoptosis, their ion channels with the potential to compromise mitochondrial functions become promising targets for the treatment of malignancies (32).

\section{Materials and methods}

Reagents. Thiazolyl blue Tetrazolium bromide (MTT), verapamil, fetal bovine serum (FBS) and 5,5',6,6'-tetrachloro1,1',3,3'-tetraethyl-imidacarbocyanine iodide (JC-1) were purchased from Sigma-Aldrich (St. Louis, MO, USA). All cell culture flasks and dishes were obtained from Corning (Corning, NY, USA). Nigericin, salinomycin, valinomycin, cyclosporine $\mathrm{A}(\mathrm{CsA})$, bongkrekic acid (BKA), $\mathrm{N}$-ethylmaleimide (NEM), 1,4-dithioerythritol (DTE) and spermine were purchased from Sigma-Aldrich. Adenosine diphosphate (ADP) was purchased from Boehringer (Mannheim, Germany). AGE provided by Wakunaga Pharmaceutical Co. Ltd. (Hiroshima, Japan) was manufactured as follows: Garlic cloves were sliced, immersed in a water-ethanol mixture solution and naturally extracted for $>10$ months at room temperature, as previously described (33). The AGE powder used in our experiments was prepared by lyophilization. It contained approximately $28.6 \%(\mathrm{w} / \mathrm{v}, 286 \mathrm{mg} / \mathrm{ml})$ solid material, $0.63 \%(6.3 \mathrm{mg} / \mathrm{ml})$ arginine and $0.1 \%$ SAC (calculated on a dry weight basis) as a marker compound for standardization (34). The AGE powder was freshly dissolved in Ham's F-12 or in RPMI-1640 medium prior to each experiment.

Cell cultures. A human colon adenocarcinoma cell line (LoVo WT) isolated from a metastatic nodule, its MDR variant (LoVo DX), a gastric adenocarcinoma cell line (AGS), a melanoma cell line (M14 WT), isolated from an epidermal melanoma, the corresponding MDR variant M14 ADR2, a human cervical adenocarcinoma cell line (HeLa) and a human ovarian carcinoma cell line (A2780) were used in this study. The LoVo, M14 and HeLa cells were a kind gift from Professor E. Dolfini (University of Milan, Milan, Italy), Dr A. Molinari (National Institute of Health, Rome, Italy) and Professor M.T. Conconi (University of Padova, Padova, Italy), respectively. The A2780 cells were purchased from ECACC (Sigma-Aldrich) cat. no. 93112519. The MDR cell line, LoVo DX, was obtained by the prolonged culture of drug-sensitive parental LoVo WT cells in medium containing doxorubicin (Adriblastina, Pharmacia \& Upjohn, Milan, Italy) as previously described by Grandi et al (35). The M14 ADR2 cell line was obtained by us (36) by culturing the M14 ADR or M14 DX cell line, previously selected for resistance to adriamycin by Molinari et al (37), in medium containing $10 \mu \mathrm{M}$ doxorubicin constantly in each passage. Both resistant cell lines are also resistant to other chemotherapeutic agents, such as etoposide and vincristine $(38,39)$. The AGS cell line (homo sapiens gastric adenocarcinoma) was obtained from 
the American Type Culture Collection (ATCC ${ }^{\circledR}$ CRL-1739 ${ }^{\mathrm{TM}}$; ATCC, Manassas, VA, USA). The LoVo and AGS cell lines were grown in Ham's F-12 medium containing glutamine supplemented with $10 \%$ FBS, $1 \%$ MEM vitamins, $1 \%$ MEM non-essential amino acid, penicillin $(100 \mathrm{U} / \mathrm{ml})$ and streptomycin $(100 \mu \mathrm{g} / \mathrm{ml})$. The M14 cells were grown in RPMI-1640 with glutamine, 10\% FBS, 1\% MEM non-essential amino acid, penicillin $(100 \mathrm{U} / \mathrm{ml})$ and streptomycin $(100 \mu \mathrm{g} / \mathrm{ml})$. The HeLa and A2780 cells were grown in Nutrient Mixture F-12 (Ham's) and RPMI-1640, respectively. In total, $1.5 \mathrm{~g} / 1$ $\mathrm{NaHCO}_{3}$ (Sigma-Aldrich), 10\% heat-inactivated fetal calf serum (Biowest, Nuaillé, France), $100 \mathrm{U} / \mathrm{ml}$ penicillin, $100 \mu \mathrm{g} / \mathrm{ml}$ streptomycin and $0.25 \mu \mathrm{g} / \mathrm{ml}$ amphotericin B (all from Sigma-Aldrich) were added to both media.

All cell lines were incubated in a humidified atmosphere of $5 \% \mathrm{CO}_{2}$ in a water-jacketed incubator at $37^{\circ} \mathrm{C}$. For each passage, exponentially growing M14 cells were harvested with $10 \mathrm{mM}$ EDTA. LoVo and AGS cells were harvested by further addition of $0.25 \%$ trypsin solution. The trypsin activity was quenched by the addition of complete F-12 medium.

AGE dose response assay. The LoVo WT, LoVo DX, M14 WT, M14 ADR2 and AGS cells were seeded in a 96-well plate and incubated for $24 \mathrm{~h}$ to allow for the complete reattachment of the cells to the plates. After changing with fresh medium, the cells were incubated in the presence of $0,1,5,7$ and $10 \mathrm{mg} / \mathrm{ml}$ AGE for 24, 48 and $72 \mathrm{~h}$. The anti-proliferative effects of AGE on human tumor cells were examined by MTT assay. Briefly, MTT was added to each well. Following $3 \mathrm{~h}$ of incubation at $37^{\circ} \mathrm{C}$, dimethyl sulfoxide was added to dissolve the crystals. The absorbance was determined at 577 and $660 \mathrm{~nm}$ using a spectrophotometer multi-mode plate reader [Synergy HT BioTek, serial no. 270204; BioTek, Bernareggio (MB), Italy].

Anti-proliferative effects of hyperthermia and AGE. The M14 WT cells were incubated in the presence of $0,1,3,6$ and $10 \mathrm{mg} / \mathrm{ml} \mathrm{AGE}$ at 37 and $42^{\circ} \mathrm{C}$ for $1 \mathrm{~h}$. After washing the cells with PBS with $1 \%$ bovine serum albumin (BSA) twice, the cells were seeded into 96-well plate and incubated in RPMI-1640 complete medium containing $0,1,3,6$ and $10 \mathrm{mg} / \mathrm{ml}$ of AGE at $37^{\circ} \mathrm{C}$ for $48 \mathrm{~h}$ followed by MTT assay as described above.

Measurements 'in situ' of mitochondrial membrane potential $(\Delta \psi m)$. The changes in $\Delta \psi \mathrm{m}$ in whole cells were assayed using the lipophilic cationic probe, JC-1 dye. The LoVo WT, LoVo DX and AGS cells were seeded in a 12-well plate and incubated for $24 \mathrm{~h}$ to allow the cells to adhere to the plates. After changing with fresh medium, the cells were incubated with $0,1,5$ and $10 \mathrm{mg} / \mathrm{ml}$ of AGE for $24 \mathrm{~h}$ at $37^{\circ} \mathrm{C}$. Subsequently, the cells were stained with $2.5 \mu \mathrm{g} / \mathrm{ml}$ of JC-1 for $20 \mathrm{~min}$ at $37^{\circ} \mathrm{C}$. In the LoVo cells, $100 \mu \mathrm{M}$ verapamil was further added to the solution in order to inhibit the P-glycoprotein-mediated efflux of JC-1 in the LoVo DX cells. Exposure to verapamil significantly increased the fluorescence intensity of JC-1 in the LoVo DX cells, while it did not affect fluorescence in LoVo WT cells. The detached cells were washed with PBS and then resuspended in PBS. The samples were then analyzed using a BD Accuri C6 flow cytometer (BD Biosciences, San Jose, CA, USA). JC-1 was excited using an argon laser at a wavelength of $488 \mathrm{~nm}$ (using a BD Accuri C6 flow cytometer). The emitted green (JC-1 monomer) and red (JC-1 aggregate) fluorescence were detected at the FL-1 channel $(533 / 30 \mathrm{~nm})$ and FL-2 channel $(585 / 40 \mathrm{~nm})$, respectively. At least 10,000 events/sample were acquired in log mode. The ratio of red (FL2)/green (FL1) fluorescence intensity was used to represent the $\Delta \psi \mathrm{m}$.

The $\Delta \psi \mathrm{m}$ of the HeLa and A2780 cells was evaluated using the $\mathrm{BD}^{\mathrm{TM}}$ MitoScreen kit (BD Pharmigen, San Diego, CA, USA) containing JC-1. The cells $\left(1.5 \times 10^{5}\right)$ were seeded in a 24-well cell culture plate. following incubation for $24 \mathrm{~h}$, AGE was added to the complete medium at 5 and $10 \mathrm{mg} / \mathrm{ml}$, and the cells were incubated for a further $72 \mathrm{~h}$. Following treatment, the cells were centrifuged at $1,000 \mathrm{x} g$ at room temperature, resuspended in JC-1 working solution and incubated for $30 \mathrm{~min}$ at $37^{\circ} \mathrm{C}$ in a $\mathrm{CO}_{2}$ incubator. Following incubation, the cells were washed twice, resuspended in assay buffer and analyzed using a FACSCanto II flow cytometer (Becton-Dickinson, Mountain View, CA, USA). The results are presented as dot plots and as the percentages of cells with an energized or depolarized mitochondrial membrane.

Animals. A total of 50 male Wistar rats, 2 months old, weighing approximately $150 \mathrm{~g}$, were used in our experiments. The rats, housed in the animal facility of the Department of Biomedical Sciences, University of Padova (Padova, Italy), were maintained under controlled conditions (temperature $20-22^{\circ} \mathrm{C}$, relative humidity $48-50 \%$, water with antibacterial control and a 12:12 h light/dark cycle) and provided with water and a standard diet (4RF25) purchased by Mucedola s.r.l., Settimo Milanese (MI), Italy.

The experimental procedures were approved by the local Ethics Committee for Animal Experimentation (CEASA) (protocol no. 3619, 15.1.2014) and performed in agreement with the international guidelines as well as European Communities Council Directive and National Regulations (CEE Council 86/609 and DL 116/92).

RLM isolation and purification. RLM were isolated using the following method: The rats were starved overnight and sacrificed by cervical dislocation. The livers were rapidly explanted, immersed in ice-cold isolation medium containing $250 \mathrm{mM}$ sucrose, $5 \mathrm{mM}$ HEPES (pH 7.4), $0.5 \mathrm{mM}$ EGTA and washed $4 / 5$ times with the same medium. The livers were minced into small sections and washed with ice-cold fresh medium without EGTA. The suspension was transferred to a glass potter and homogenized using a Teflon pestle operating at 1,600 rpm, by 3-4 time strokes.

The homogenate was centrifuged at $700 \mathrm{xg}$ for $5 \mathrm{~min}$ at $4{ }^{\circ} \mathrm{C}$ and the obtained supernatant was centrifuged at $10,800 \mathrm{x}$ for $10 \mathrm{~min}$ at $4^{\circ} \mathrm{C}$. The pellet was washed with isolation medium, resuspended and centrifuged at $15,900 \mathrm{xg}$ for $10 \mathrm{~min}$ at $4^{\circ} \mathrm{C}$. Finally, the obtained pellet, containing the mitochondria, was suspended in the standard medium (see the incubation procedure) (40). Mitochondrial proteins were measured by the biuret method with BSA, as a standard (41).

The mitochondria $(1 \mathrm{mg}$ protein $/ \mathrm{ml})$ were incubated in a water-jacketed cell at $25^{\circ} \mathrm{C}$ under continuous stirring. The standard medium contained $250 \mathrm{mM}$ sucrose, $10 \mathrm{mM}$ HEPES (pH 7.4), $5 \mathrm{mM}$ Na-succinate, $1.25 \mu \mathrm{M}$ rotenone and $1 \mathrm{mM}$ Na-phosphate. Variations and/or other additions are provided with each experiment. 
Determination of mitochondrial functions. $\Delta \psi \mathrm{m}$ was calculated on the basis of the distribution of the lipid-soluble cation tetraphenylphosphonium $\left(\mathrm{TPP}^{+}\right)$(Sigma-Aldrich) measured across the inner membrane using a $\mathrm{TPP}^{+}$-selective electrode (42). Mitochondrial swelling was determined by measuring the apparent absorbance change of mitochondrial suspensions at $540 \mathrm{~nm}$ on a Kontron Uvikon model 922 spectrophotometer equipped with thermostatic control. The protein sulfydryl oxidation assay was performed as previously described by Santos et al (43). $\mathrm{K}^{+}$was estimated in the supernatant by atomic spectroscopy as previously described by Crompton and Costi (44).

Nigericin, salinomycin, valinomycin are antibiotics that behave as ionophores for $\mathrm{K}^{+}$in the mitochondria. They were all used at a $1 \mu \mathrm{M}$ concentration, for approximately $10 \mathrm{~min}$, to compare their effects with that of AGE. $\mathrm{Mg}^{2+}$ was used at a $1 \mathrm{mM}$ concentration for approximately $10 \mathrm{~min}$ of incubation, as an inhibitor of $\mathrm{K}^{+} / \mathrm{H}^{+}$exchanger. CsA is an immunosuppressant, while BKA is an inhibitor of AdNT, and both were used at a $1 \mu \mathrm{M}$ concentration. ADP is a nucleotide, a substrate of AdNT, and was used at a $1 \mathrm{mM}$ concentration. All these compounds were used, for approximately $30 \mathrm{~min}$ of incubation, as inhibitors of MPT. NEM, used at $10 \mathrm{mM}$ concentration, is a thiol reagent, DTE, used at $1 \mathrm{mM}$ concentration, is a reducing agent, while spermine, at $50 \mu \mathrm{M}$, is a ROS scavenger. These compounds were incubated for approximately $40 \mathrm{~min}$, and used as MPT inhibitors.

Statistical analysis. The data were presented as the means \pm SEM or means \pm SD. Statistical analysis was performed using one-way ANOVA with the Tukey-Kramer post hoc test was used. A P-value $<0.05$ was considered to indicate a statistically significant difference.

\section{Results}

Anti-proliferative effects of AGE on sensitive and MDR human cancer cell lines. The results of MTT assays revealed that treatment with AGE exerted anti-proliferative effects on all cell lines examined in a dose-dependent manner. Treatment with $10 \mathrm{mg} / \mathrm{ml}$ of AGE for $72 \mathrm{~h}$ decreased the viability of both the LoVo WT and LoVo DX cells to 73 and $65 \%$, respectively, when compared with the untreated control cells (Fig. 1A and B). The proliferation of the M14 WT and M14 ADR2 cells was markedly decreased to approximately $43 \%$ of the control level following treatment with $10 \mathrm{mg} / \mathrm{ml}$ AGE for only $24 \mathrm{~h}$ (Fig. 1C and D). A further extension of the incubation time did not affect the viability of the cells. Long-term treatment with $>5 \mathrm{mg} / \mathrm{ml}$ of AGE induced a marked inhibitory effect on growth of the AGS cells (Fig. 1E). An amount of AGE $<5 \mathrm{mg} / \mathrm{ml}$ exerted a modest effect on all cell lines.

Anti-proliferative effects of hyperthermia and AGE. The sensitivity of numerous cancer cell lines to an increase in the temperature $>37^{\circ} \mathrm{C}$ is the basis of clinical hyperthermia. The potential of AGE to enhance the cytotoxic effects of hyperthermia was investigated in the M14 cells as shown in Fig. 2. Incubation at $42^{\circ} \mathrm{C}$ for $1 \mathrm{~h}$ suppressed the viability of the M14 WT cells by approximately $29 \%$ (data not shown). The
M14 WT cells treated with $10 \mathrm{mg} / \mathrm{ml}$ of $\mathrm{AGE}$ at $42^{\circ} \mathrm{C}$ for $1 \mathrm{~h}$ exhibited a decrease in viability to $25 \%$ when compared to the untreated cells at the same temperature, while $10 \mathrm{mg} / \mathrm{ml} \mathrm{AGE}$ at $37^{\circ} \mathrm{C}$ decreased cell viability only to $49 \%$ of the untreated cells.

Depolarization of $\Delta \psi m$ induced by $A G E$ in whole human cancer cells. To obtain information on mitochondrial functionality, a flow cytometric analysis of the control and treated cells loaded with the mitochondrial probe, JC-1, was performed on several cancer cell lines. Flow cytometric analysis revealed a tendency that AGE exerted toxic effects on the mitochondria in a dose-response manner in the LoVo WT, LoVo DX and AGS cells. Treatment with AGE induced an evident mitochondrial membrane depolarization that was higher in the AGS cells than in the LoVo WT and LoVo DX cells, as indicated by the ratio of red (FL2 emission)/green (FL1 signal) fluorescence intensity (Fig. 3).

A similar effect was also obtained when incubating the ovarian carcinoma A2780 (Fig. 4A) and cervical adenocarcinoma HeLa (Fig. 4B) cells in the presence of various concentrations of AGE ( 5 and $10 \mathrm{mg} / \mathrm{ml}$ ) for $72 \mathrm{~h}$. The decrease in red fluorescence in the dot plots of the treated cells indicated mitochondrial membrane depolarization. Nevertheless, the extent of the effect appeared to differ markedly between the two cell lines taken into consideration. In particular, AGE induced a detectable effect from the concentration of $5 \mathrm{mg} / \mathrm{ml}$ on the A2780 cells, with a percentage of cells exhibiting depolarized mitochondria that increased from $0.6 \%$ (untreated cells) to $4.0 \%$ (Fig. 4A). The ability of AGE to induce mitochondrial membrane depolarization was clearly confirmed at the maximum concentration considered, and indeed, at $10 \mathrm{mg} / \mathrm{ml}$, the above-mentioned percentage increased to $85.4 \%$. In the HeLa cells, the ability of AGE to provoke mitochondrial depolarization was markedly less pronounced. Nevertheless, a dose-dependent effect was also observed in this cell line, with the percentage of cells exhibiting mitochondrial membrane depolarization increasing from $6.4 \%$ (untreated) to 8.6 and $9.1 \%$ in the presence of AGE at 5 and $10 \mathrm{mg} / \mathrm{ml}$, respectively.

Activation of the mitochondrial $K^{+} / H^{+}$exchanger by AGE. RLM incubated in standard medium at the concentration of $1 \mathrm{mg}$ protein $/ \mathrm{ml}$, as described in the Materials and methods, and energized by the oxidation of succinate in the presence of rotenone, exhibited a $\Delta \psi \mathrm{m}$ value of approximately $180 \mathrm{mV}$ (Fig. 5, curve a). The addition of AGE at $0.5 \mathrm{mg} / \mathrm{ml}$ induced a hyperpolarization of approximately $15 \mathrm{mV}$ that was maintained for several minutes (Fig. 5, curve b). This effect was similar to that observed with the ionophore, nigericin (45) (Fig. 5, curve c) and with the anticancer drug salinomycin (Fig. 5, curve d) (46). The presence of AGE also induced the release of $\mathrm{K}^{+}$into the incubation medium (Fig. 5, insert). Higher AGE concentrations did not significantly increase $\Delta \psi \mathrm{m}$ (Fig. 8, below). The addition of another ionophore, valinomycin, after AGE, decreased the $\Delta \psi \mathrm{m}$ to the same value obtained prior to the addition of AGE (Fig. 6A, curve a). Indeed, the addition of $\mathrm{K}^{+}$induced a further decrease in $\Delta \psi \mathrm{m}$ to a greater extent (Fig. 6A, curve b) (47). These results indicated that the addition of valinomycin provoked the electrophoretic uptake of $\mathrm{K}^{+}$previously released by AGE (Fig. 5, insert) and 
A

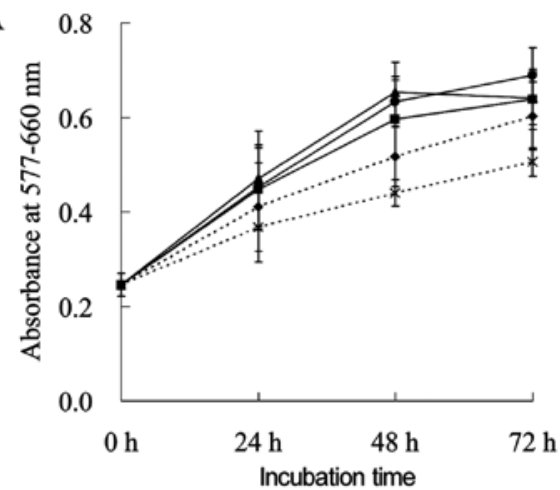

C

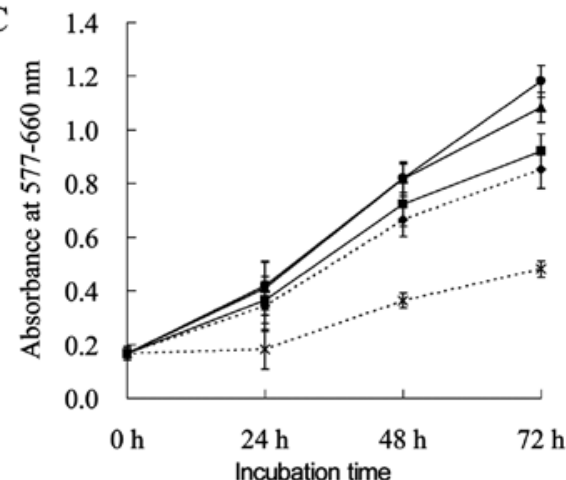

E

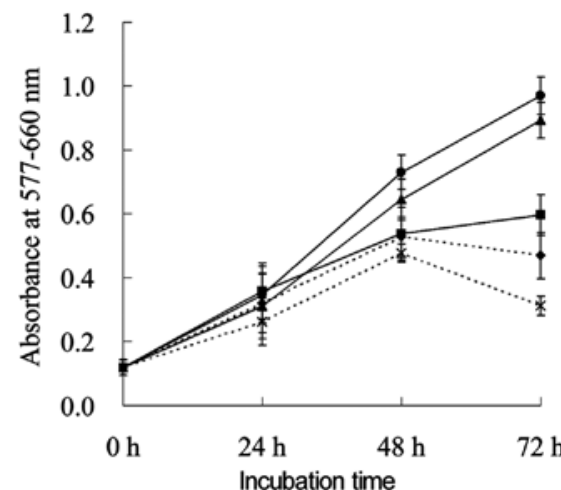

B

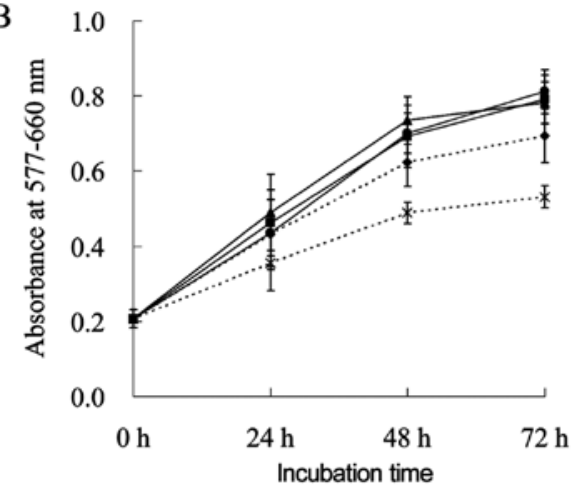

D

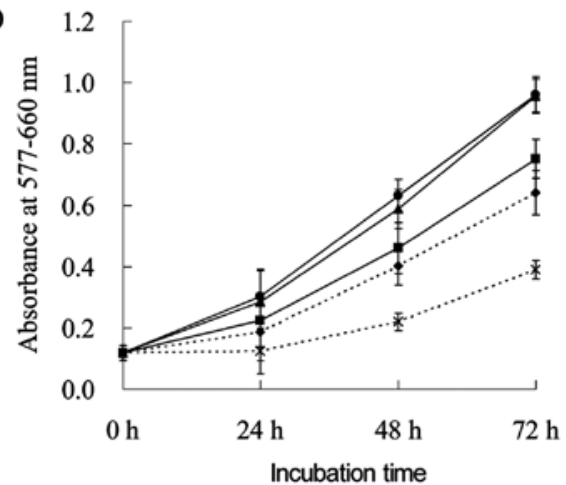

Figure 1. Anti-proliferative effects of AGE on human tumor cells. (A) LoVo WT, (B) LoVo DX, (C) M14 WT, (D) M14 ADR2 and (E) AGS cells were treated with $0,1,5,7$ and $10 \mathrm{mg} / \mathrm{ml}$ of AGE alone for 24,48 and $72 \mathrm{~h}$. The effects were determined by MTT assay. Each point represents the mean \pm SEM of 2 independent experiments, with 3 wells per experiments. Where not shown, error bars lie within symbols. AGE, aged garlic extract.

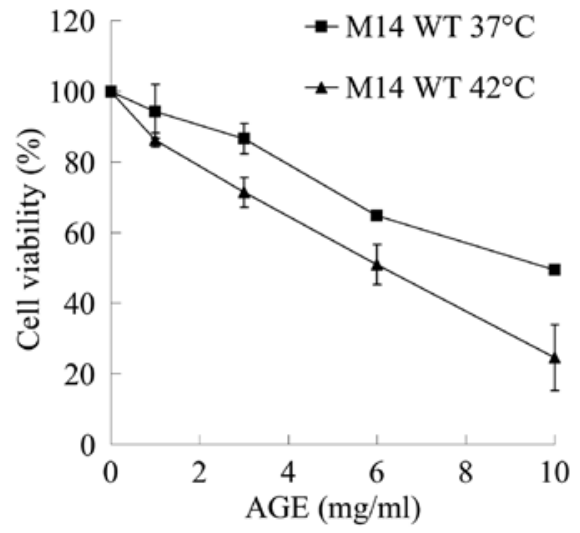

Figure 2. Anti-proliferative effects of hyperthermia and AGE. M14 WT cells were incubated in the presence of $\mathrm{AGE}$ at 37 or $42^{\circ} \mathrm{C}$ for $1 \mathrm{~h}$. Subsequently, the cells were incubated in the presence of $\mathrm{AGE}$ at $37^{\circ} \mathrm{C}$ for $48 \mathrm{~h}$ followed by MTT assay. Each point represents the mean \pm SEM of 2 independent experiments, with 3 wells per experiments. Where not shown, error bars lie within symbols. AGE, aged garlic extract.

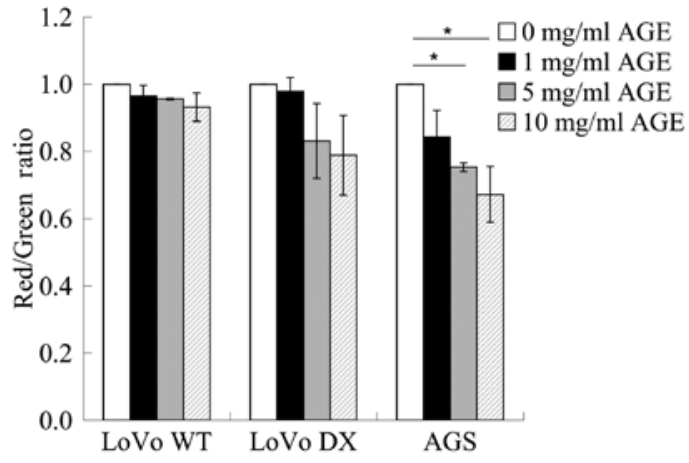

Figure 3. Mitochondrial membrane potential induced by treatment with AGE in LoVo and AGS cells. LoVo and AGS cells were incubated with AGE for $24 \mathrm{~h}$ at $37^{\circ} \mathrm{C}$. Subsequently, mitochondrial membrane depolarization was assayed using JC-1. The ratio of red (JC-1 aggregate)/green (JC-1 monomer) fluorescence intensity was used to represent the mitochondrial membrane potential. Results represent the mean values \pm SD from 3 independent experiments. ${ }^{*} \mathrm{P}<0.05$ versus unstimulated cells, determined by ANOVA with the Tukey-Kramer post hoc test. AGE, aged garlic extract. 


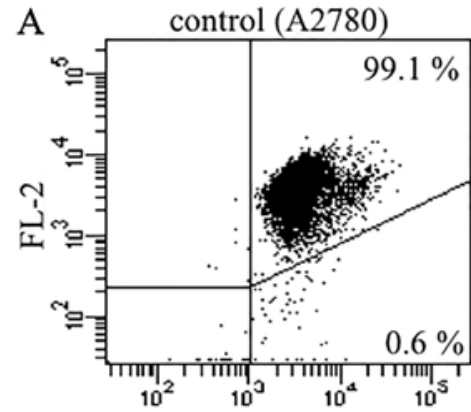

FL-1
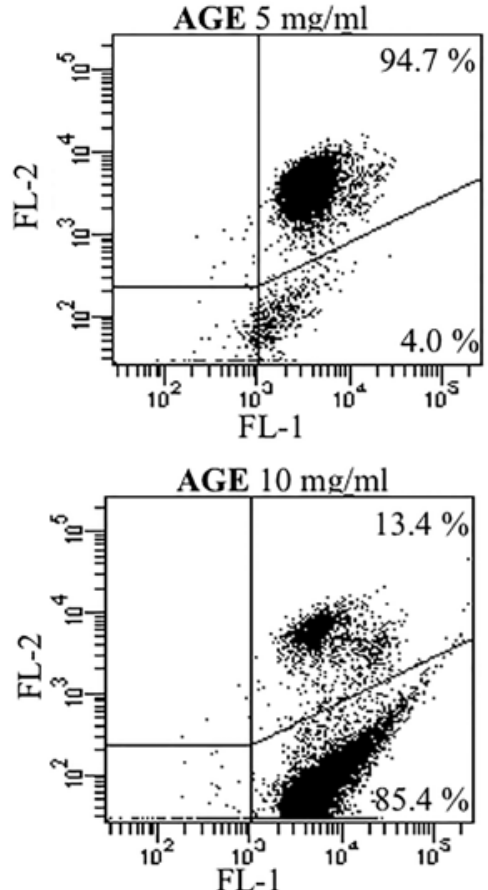

$\mathrm{B}$
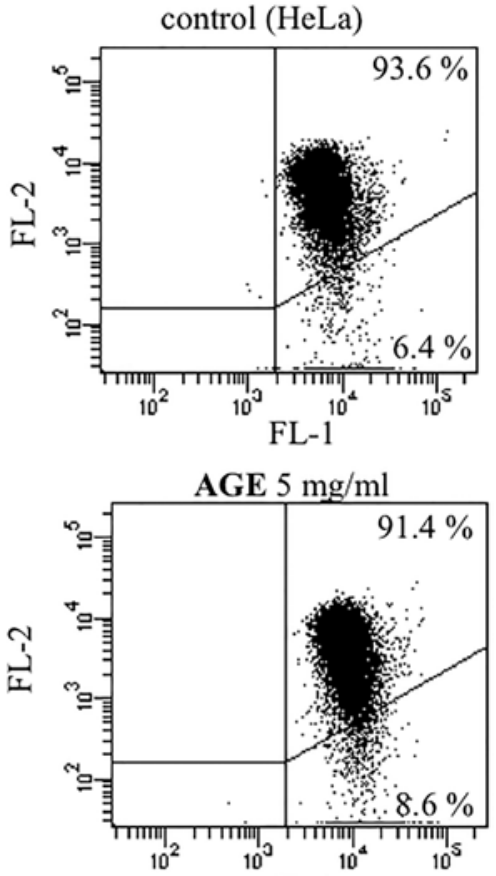

FL-1

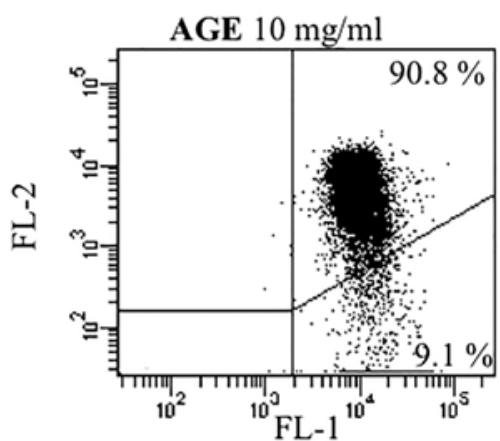

Figure 4. Mitochondrial membrane potential induced by treatment with AGE in A2780 and HeLa cells. (A) A2780 or (B) HeLa cells were treated for $72 \mathrm{~h}$ with AGE at the indicated concentrations, and stained with JC-1. Results are from a representative experiment, and shown as dot plots and percentage of cells with energized (top) and depolarized (bottom) mitochondrial membrane. Three other experiments yielded the same result. AGE, aged garlic extract.

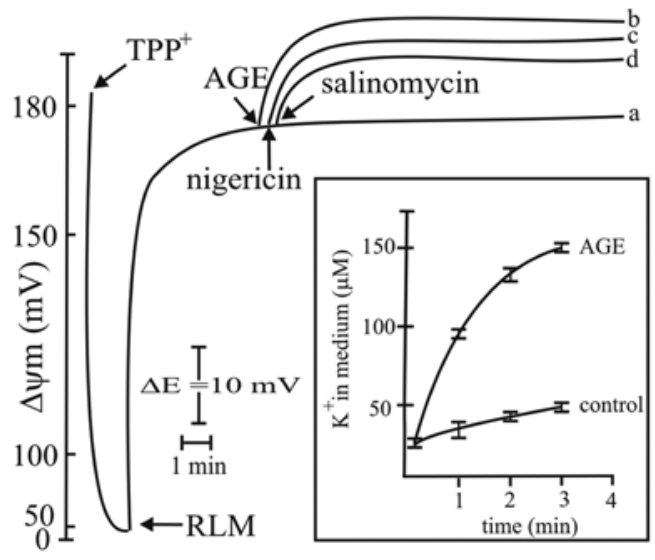

Figure 5. Effect of AGE on $\Delta \psi \mathrm{m}$. Comparison with nigericin or salinomycin. RLM were incubated for $15 \mathrm{~min}$ in standard medium as described in the Materials and methods. Where indicated, $0.5 \mathrm{mg} / \mathrm{ml}$ AGE, $1 \mu \mathrm{M}$ nigericin or $1 \mu \mathrm{M}$ salinomycin were added. $\operatorname{TPP}^{+}(1 \mu \mathrm{M})$ was added to the medium for $\Delta \psi \mathrm{m}$ measurements. $\Delta \mathrm{E}$ electrode potential. Six additional experiments exhibited the same trend. The inset shows the release of endogenous $\mathrm{K}^{+}$ induced by AGE. RLM were incubated in the same standard medium, as above, in the presence of $0.5 \mathrm{mg} / \mathrm{ml}$ AGE. Mean values \pm SD of 3 different experiments are shown. $\Delta \psi \mathrm{m}$, mitochondrial membrane potential; RLM, rat liver mitochondria; $\mathrm{TPP}^{+}$, tetraphenylphosphonium; AGE, aged garlic extract. are in close agreement with the mechanisms of the effect of valinomycin (Fig. 6A, curve c) that induces an electrophoretic uptake of exogenous $\mathrm{K}^{+}$driven by $\Delta \psi \mathrm{m}$ (Fig. 7). Most probably, valinomycin was more efficient in inducing a decrease in $\Delta \psi \mathrm{m}$ with respect to the increased hyperpolarization induced by AGE. The observed effect of AGE may be explained by considering the mechanisms of action of the above-mentioned antibiotics (nigericin and salinomycin) on the mitochondrial membrane that activates an exchange between endogenous $\mathrm{K}^{+}$and exogenous $\mathrm{H}^{+}$, as schematically depicted in Fig. 7. This exchange takes place to a large extent, due to the mitochondrial matrix that contains high concentrations of $\mathrm{K}^{+}$ (approximately $150 \mathrm{mM}$ ). Thus, the electrochemical gradient $\left(\Delta \mu_{\mathrm{H}}{ }^{+}\right)$, that is the sum of the electrical and chemical gradient $\left(\Delta \mu_{\mathrm{H}}{ }^{+}=\Delta \psi+\Delta \mathrm{pH}\right)$, is completely transformed in a $\mathrm{K}^{+}$gradient, $\Delta \mu_{\mathrm{K}}{ }^{+}\left(\Delta \mu_{\mathrm{H}}{ }^{+}=\Delta \mu_{\mathrm{K}}{ }^{+}\right)$. Under this consideration, the large uptake of $\mathrm{H}^{+}$completely collapses $\Delta \mathrm{pH}$, with a strong acidification of the matrix, and $\mathrm{K}^{+}$gradient $\Delta \mu_{\mathrm{K}}^{+}$(that is $\Delta \mu_{\mathrm{H}}^{+}$) becomes equal to $\Delta \psi \mathrm{m}$. This explains the observed increase in $\Delta \psi \mathrm{m}$ following the addition of nigericin, salinomycin, and likely also of AGE. Most probably, the effect of AGE was attributable to an activation of the mitochondrial $\mathrm{K}^{+} / \mathrm{H}^{+}$exchanger, 
$\mathbf{A}$

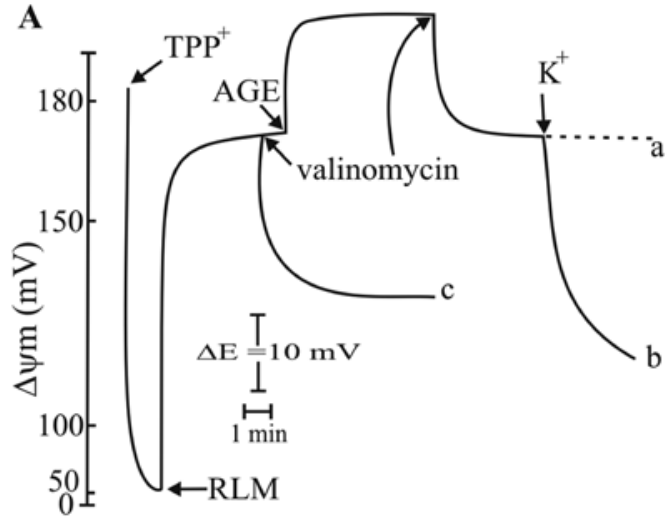

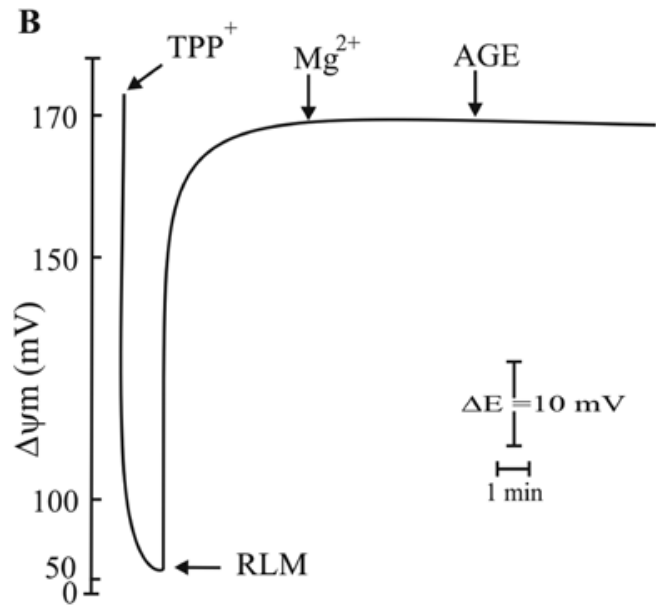

Figure 6. Effect of valinomycin on $\Delta \psi \mathrm{m}$ of RLM in the presence or absence of AGE. (A) Prevention by $\mathrm{Mg}^{2+}$ on the effect of AGE on $\Delta \psi \mathrm{m}$. (B) RLM were

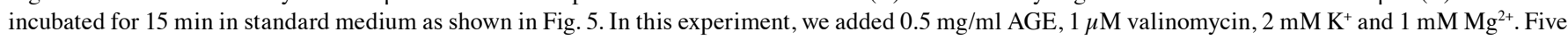
additional experiments exhibited the same trend. $\Delta \psi \mathrm{m}$, mitochondrial membrane potential; RLM, rat liver mitochondria; AGE, aged garlic extract.

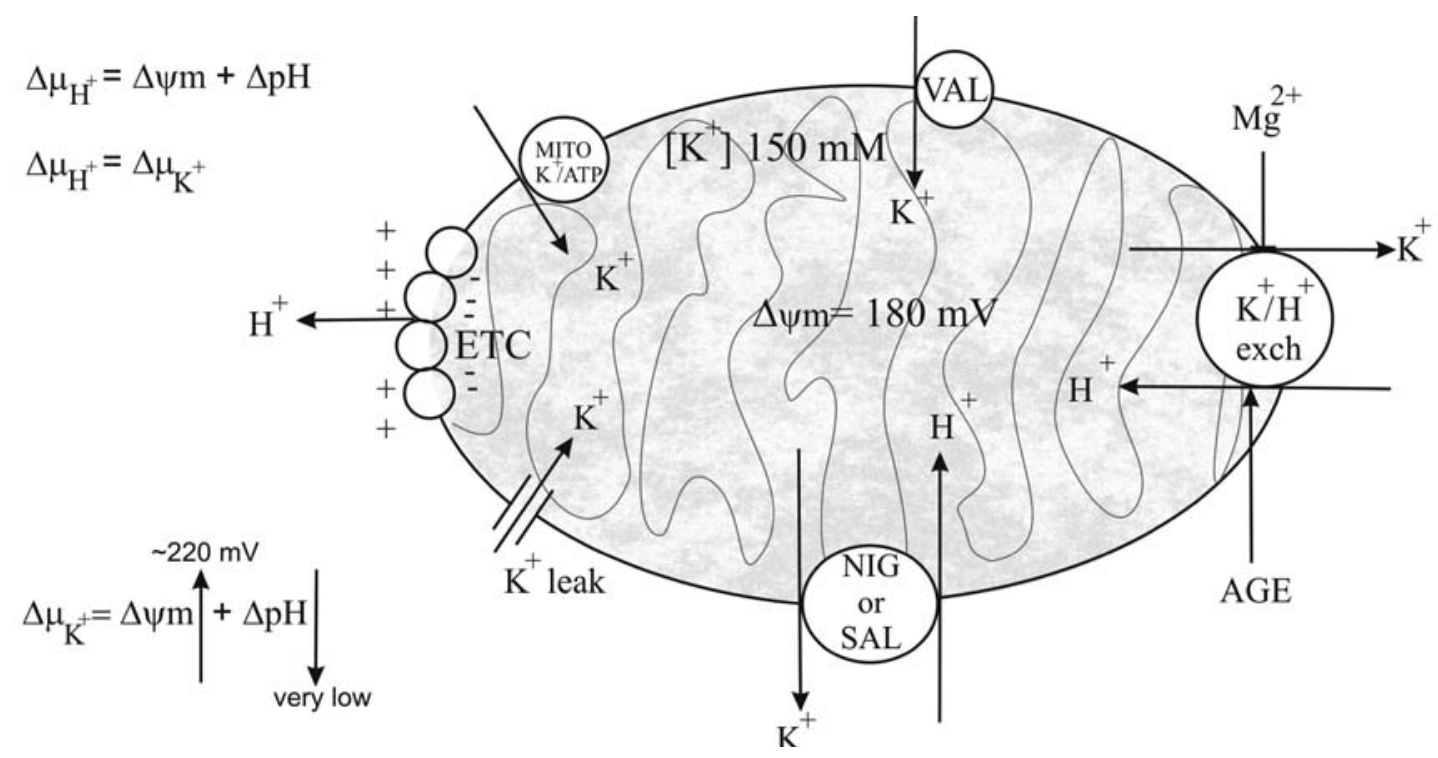

Figure 7. Schematic diagram showing the activity of $\mathrm{K}^{+} / \mathrm{H}^{+}$exchanger, $\mathrm{K}^{+}$transporters, electron transport chain and the effects of AGE and ionophores (see description in the text). $\Delta \psi \mathrm{m}$, mitochondrial membrane potential; NIG, nigericin; SAL, salinomycin; AGE, aged garlic extract.

while nigericin and salinomycin act as ionophores, forming a channel on the membrane for $\mathrm{K}^{+} / \mathrm{H}^{+}$exchange. The effects of AGE on the $\mathrm{K}^{+} / \mathrm{H}^{+}$exchanger were strongly supported by the observations that after its addition to the RLM, a rapid release of $\mathrm{K}^{+}$was induced (Fig. 5, insert).

These results demonstrate that AGE induces the $\mathrm{K}^{+} / \mathrm{H}^{+}$ exchange, similar to nigericin or salinomycin, but through a different mechanism. A further confirmation of this effect is represented by the results reported in Fig. 6B. In fact, a previous addition of $1 \mathrm{mM} \mathrm{Mg}^{2+}$ to RLM completely prevented the increase in $\Delta \psi \mathrm{m}$ caused by $\mathrm{AGE} . \mathrm{Mg}^{2+}$ has been reported to be a strong inhibitor of the $\mathrm{K}^{+} / \mathrm{H}^{+}$exchanger (48). The authors proposed $\mathrm{Mg}^{2+}$ as a 'carrier brake' of the exchanger. Indeed the inhibition on $\mathrm{K}^{+} / \mathrm{H}^{+}$exchanger by $\mathrm{Mg}^{2+}$ confirmed that AGE acts on the $\mathrm{K}^{+} / \mathrm{H}^{+}$exchanger.

Induction of mitochondrial permeability transition following prolonged incubation of the RLM with AGE. As shown in Fig. 8, the prolonged incubation of RLM with various concentrations of AGE, until $40 \mathrm{~min}$, a decrease in $\Delta \psi \mathrm{m}$ to a varying extent. This observation appeared to be in contrast to the results reported in Fig. 6A, showing that AGE stimulated an increase in $\Delta \psi \mathrm{m}$. In fact, the decrease in $\Delta \psi \mathrm{m}$ began after several minutes of incubation and was dependent on the AGE concentration. The decrease in $\Delta \psi \mathrm{m}$ could be ascribable to the strong acidification of mitochondrial matrix following $\mathrm{H}^{+}$ uptake in exchange with $\mathrm{K}^{+}$that damages RLM. However, the collapse of $\Delta \psi \mathrm{m}$ may be due also to another event. In this regard, it was also found that the incubation of RLM with AGE, for approximately $15 \mathrm{~min}$, caused mitochondrial swelling to a large extent (Fig. 9). This swelling was inhibited by CsA, BKA and ADP (Fig. 9), that are typical inhibitors of the mitochondrial permeability transition (MPT), a phenomenon closely related to cell death by intrinsic apoptosis. Generally, this phenomenon is induced in the presence of supraphysiological $\mathrm{Ca}^{2+}$ concentrations (primary inducer) and an oxidizing agent 


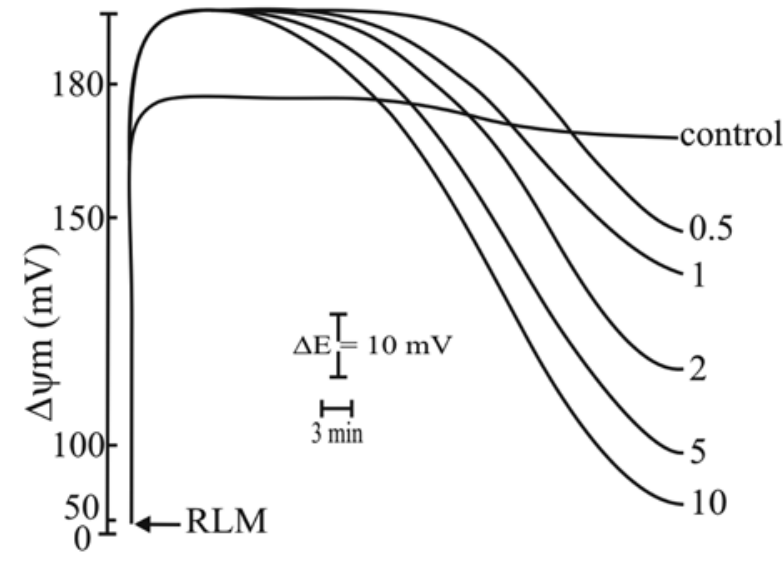

Figure 8. Dose-dependent effect of AGE on $\Delta \psi \mathrm{m}$. RLM were incubated for $40 \mathrm{~min}$ in standard medium as shown in Fig. 5. AGE was present in the incubation medium at concentrations $(\mathrm{mg} / \mathrm{ml})$ indicated on the side of the curves. Five supplementary experiments exhibited the same trend. $\Delta \psi \mathrm{m}$, mitochondrial membrane potential; RLM, rat liver mitochondria; AGE, aged garlic extract.

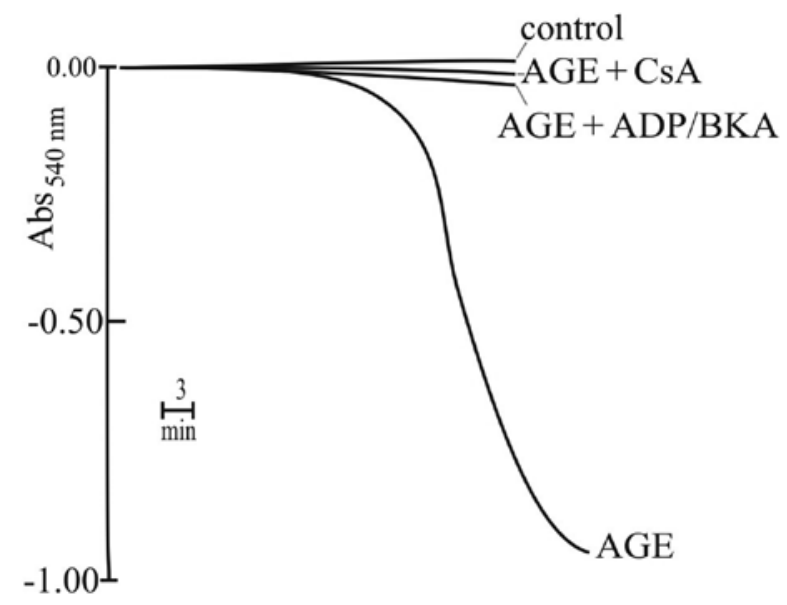

Figure 9. AGE induces mitochondrial swelling of large amplitude. Also shown are the inhibitory effects of CsA, ADP and BKA. RLM were incubated for $40 \mathrm{~min}$ as shown in Fig. 5. AGE was present at $1 \mathrm{mg} / \mathrm{ml}$. When present: $1 \mu \mathrm{M}$ CsA, $1 \mathrm{mM}$ ADP, $1 \mu \mathrm{M}$ BKA. Downward deflection: Mitochondrial swelling. Five other experiments exhibited almost identical results. AGE, aged garlic extract; CsA, cyclosporin A; BKA, bongkrekic acid; ADP, adenosine diphosphate.

(secondary inducer or amplifier) (for reviews see refs. 49,50). However, $\mathrm{Ca}^{2+}$ was not added to the incubation medium; nevertheless, another experiment revealed that ruthenium red (RR), an inhibitor of $\mathrm{Ca}^{2+}$ transport, completely prevented mitochondrial swelling (data not shown). This indicates that in the presence of AGE, RR acts on MPT by an unknown mechanism that, however, does not involve exogenous $\mathrm{Ca}^{2+}$. A first conclusion of these results is that $\mathrm{AGE}$, following prolonged incubation, induced MPT of large amplitude, as confirmed by the complete prevention due to the MPT inhibitors.

Oxidizing effects induced by AGE on the mitochondria. The experiment shown in Fig. 10 was performed in order to evaluate whether MPT was also related to oxidative stress. As shown in the figure, AGE induced a decrease in the mitochondrial sulfydryl groups with a dose response-dependent mechanism. Thus, this observation may demonstrate that AGE acts as an oxidant with the generation of disulfide bridge (see Discussion).

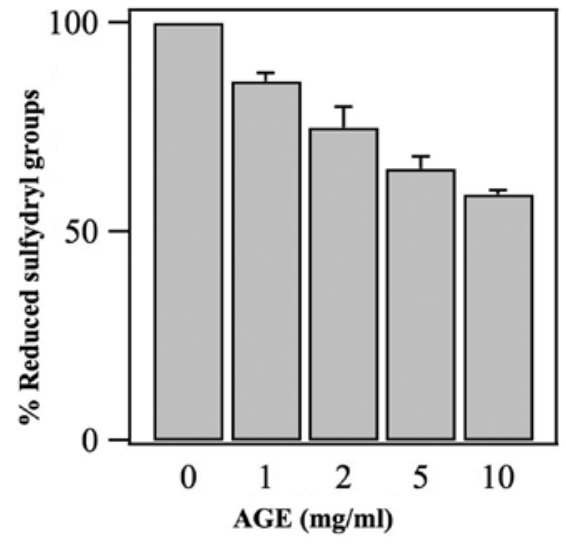

Figure 10. Dose-dependent effect of AGE on sulfydryl groups. RLM were incubated for $40 \mathrm{~min}$ as shown in Fig. 5. AGE was present in the incubation medium at the concentrations reported in the histogram. Mean values $\pm \mathrm{SD}$ of 5 experiments are reported. AGE, aged garlic extract.

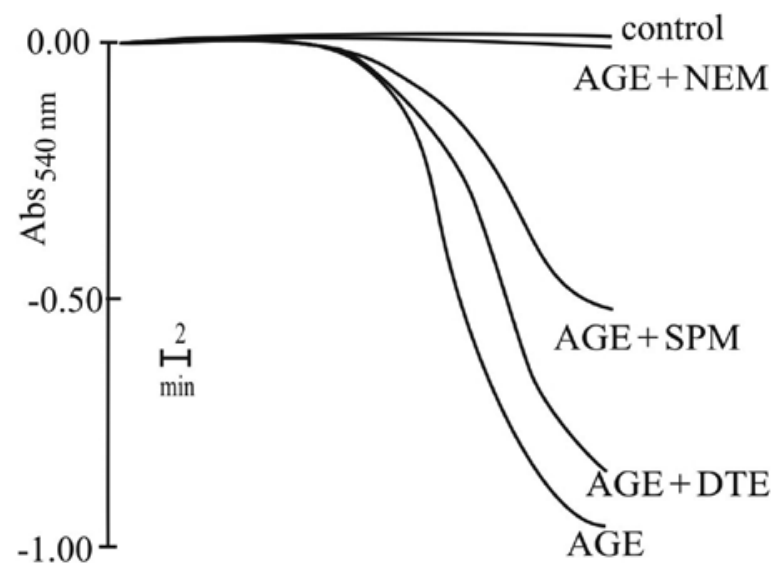

Figure 11. Effects of anti-oxidizing agents on mitochondrial swelling induced by AGE. RLM were incubated in standard medium as shown in Fig. 9. AGE was present at $1 \mathrm{mg} / \mathrm{ml}$. When present: $10 \mu \mathrm{M}$ NEM, $50 \mu \mathrm{M}$ spermine (SPM), $1 \mathrm{mM}$ DTE. Five other experiments exhibited almost identical results. AGE, aged garlic extract; RLM, rat liver mitochondria; NEM, N-ethylmaleimide; SPM, spermine; DTE, 1,4-dithioerythritol.

To support this result, another experiment on mitochondrial swelling induced by AGE, in the presence of antioxidant agents was performed. The results reported in Fig. 11 indicated that the alkylating reagent, NEM, completely prevented the swelling, while the reducing agent, DTE, or the scavenger of ROS, spermine, exerted negligible or only partial inhibitory effects, respectively. Very surprisingly, AGE was able to induce oxidative stress; however, MPT induction was not closely related to this event. Most probably, the oxidation of the SH groups by AGE was only partially involved in the induction of MPT, as demonstrated by the ineffectiveness of DTE and spermine. Of note, the inhibitory effects induced by NEM warrant further investigation.

\section{Discussion}

In conventional cancer chemotherapy, numerous issues hamper successful treatment. Among these, the lack of tumor specificity of the cytotoxic drugs, and the development of MDR cancer cells are the most difficult issues which need 
to be resolved. Hence, there is a demand for alternative therapeutic strategies. Treatment of the AGS, HeLa, A2780, LoVo WT and LoVo DX cells with AGE was accompanied by characteristic mitochondrial alterations. JC-1 exposure on the outer surface of the mitochondrial membrane clearly revealed the onset of the mitochondrial membrane depolarization process (Figs. 3 and 4). In general, the mitochondrial changes of the AGS, LoVo WT cells and its resistant phenotype mirrored the results of the cell survival experiments (Fig. 1).

The presence of AGE near the tumor mass may enhance the effects of currently used antineoplastic therapies, such as hyperthermia therapy. Therefore, from a therapeutic point of view, the improvement of the efficacy of the in situ presence of cytotoxic drugs is essential. As reported above, AGE induced a decrease in the viability of the melanoma M14 WT cells (Fig. 1C). Of note, a considerable enhancement of cytotoxicity at $42^{\circ} \mathrm{C}$, compared to $37^{\circ} \mathrm{C}$, was also observed (Fig. 2). It has been reported that cancer cells are selectively killed by hyperthermia alone (51). Moreover, numerous studies have demonstrated a beneficial antineoplastic effect of hyperthermia, particularly when used in combination with anticancer agents or associated with other therapeutic modalities, such as irradiation or chemotherapy, in the treatment of human cancers $(39,52,53)$. This has led researchers to evaluate the clinical potential of hyperthermia using several temperatures (ranging from 40 to $43^{\circ} \mathrm{C}$ ) $(51)$. Localized hyperthermia enhances the cytotoxic process of several antitumor drugs and has considerable potential in cancer therapy $(54,55)$. This has been explained by a favourable influence on blood flow, cell membrane permeability and drug uptake (56). Hyperthermia can act at the initial stage of treatment, probably by accelerating the kinetics of the membrane molecular interactions and by favouring drug delivery into the cancer cells $(51,57)$. In view of these results, the use of AGE in cancer therapy deserves to be taken into consideration. By delivering AGE into cancer cells, a cytotoxic effect can be induced in situ. The main challenge is the mechanism through which AGE can be delivered in vivo to cancer cells for possible clinical application. Molecular anticancer drugs can be conjugated with biocompatible polymers which function as carriers and stabilizers, resulting in decreased drug toxicity and an enhanced therapeutic efficacy (58). It has been shown that by conjugating macromolecules with polyethylene glycol (PEG) hydrogels, with the aim of increasing its plasmatic half-life or its targetability under administrable form, the yield of immobilization is very high (59). Currently, nanotechnology concerning particles and devices in the range of a 1-100 $\mathrm{nm}$ dimension, provides novel opportunities in cancer therapy. Nanoparticlebased therapies have been shown to reduce systemic toxicities and to enhance therapeutic efficacy of drugs $(60,61)$. Our research group has previously performed several studies into the research of novel nanoparticles in inducing polyamine and bovine serum amine oxidase (BSAO)-based nanoparticles to overcome some of the issues associated with conventional anticancer therapy, including the limitations of treating drug resistant tumors (62). To increase the stability of the enzyme and the release of cytotoxic products, core-shell gold nanoparticles have been employed for the immobilization of BSAO (63). BSAO was also conjugated on a new injectable nanohydrogel, obtained derivatizing hyaluronic acid with cholesterol (64). The results indicate that the above-mentioned nanosystems and the superparamagnetic and iron oxide nanoparticles (65) are useful controlled delivery systems, promising for future biomedical enzyme applications. Moreover, in our opinion, the systematic exploration of AGE in combination with conventional anticancer drugs promises new and efficient anticancer therapies within a short period of time.

As regards the mechanisms of action, the results obtained by this study first of all strongly support the hypothesis that AGE functions in a similar manner as $\mathrm{K}^{+}$ionophores, such as nigericin or salinomycin (46) (Fig. 5), and opposite to that of another $\mathrm{K}^{+}$ionophore valinomycin (47) (Fig. 6A). In particular, AGE acts in the mitochondria as a $\mathrm{K}^{+} / \mathrm{H}^{+}$antiporter that directly affects some mitochondrial bioenergetic functions, not only a few minutes later upon its addition, but also after longer incubation times.

Thus, these results clearly demonstrate that AGE is able to interact at the mitochondrial $\mathrm{K}^{+}$cycle level. The $\mathrm{K}^{+}$ cycle consists of influx and efflux pathways for $\mathrm{K}^{+}, \mathrm{H}^{+}$and anions (Fig. 7). It is well known that electrogenic proton ejection, by the electron transport chain, generates an electrical membrane potential $\left(\Delta \mu_{\mathrm{H}}{ }^{+}\right)$which drives $\mathrm{K}^{+}$influx by diffusion (' $\mathrm{K}^{+}$leak') and via the mitochondrial ATP-sensitive $\mathrm{K}^{+}$channel (mito $\mathrm{K}_{\text {ATP }}$ ) (Fig. 7). This $\mathrm{K}^{+} / \mathrm{H}^{+}$exchange will alkalinize the matrix causing the uptake of phosphate via the electroneutral $\mathrm{Pi}-\mathrm{H}^{+}$symporter. Net uptake of $\mathrm{K}^{+}$will be accompanied by osmotically obligated water that would result in matrix swelling. However, excess matrix $\mathrm{K}^{+}$is ejected by the $\mathrm{K}^{+} / \mathrm{H}^{+}$antiporter that prevents mitochondrial swelling, thus maintaining matrix volume homeostasis (66). Therefore, the mitochondrial $\mathrm{K}^{+}$cycle plays two distinct roles in mitochondrial and cell physiology: i) Volume homeostasis to prevent excessive matrix swelling; ii) volume regulation to prevent excessive matrix contraction (67). Changes in the regulated activity of mito $\mathrm{K}_{\mathrm{ATP}}, \mathrm{K}^{+}$leak or $\mathrm{K}^{+} / \mathrm{H}^{+}$antiporter can lead to matrix swelling or contraction with catastrophic effect on inner membrane, and to vesicular system assembly. This can lead to dysfunctions of mitochondrial complexes and can alter electron flux with the generation of ROS $(68,69)$ and consequent bioenergetic collapse. On the basis of the reported results, the effects of AGE on the mitochondria exhibited a close correlation with nigericin and salinomycin and are comparable to the above-mentioned changes in the activity of the $\mathrm{K}^{+}$cycle.

Considering the above-mentioned correlation, in particular, the acidification of mitochondrial matrix due to the $\mathrm{H}^{+}$ influx, it is possible to propose, besides the above-mentioned alterations of inner membrane, other pathophysiological effect for AGE. Matrix $\mathrm{pH}$ is a factor that controls oxidative phosphorylation in the mitochondria of normal cells. Its value ranges from 7.7 to 8.2 in different cell types, while the $\mathrm{pH}$ of cytosol is approximately 7.0. This $\Delta \mathrm{pH}$ contributes in significant way to the driving force for ATP synthesis, but also for several transport processes responsible for exchanging metabolites (e.g., phosphate, pyruvate and glutamate) (70). Hence, matrix acidification induced by AGE addition attenuates mitochondrial ATP synthesis, despite hyperpolarization of the membrane observed in the first 10-20 min. In fact, the prolonged acidification alters the activity of the enzymes of Krebs cycle and respiratory chain causing a sustained decrease in oxygen consumption and a decrease in $\Delta \psi \mathrm{m}$, the extent of which depends on AGE concentration (Fig. 8). 
Apart from considering the effect of AGE as a $\mathrm{K}^{+} / \mathrm{H}^{+}$ exchanger, its action following prolonged incubation should also be taken into account, leading to mitochondrial swelling and $\Delta \psi \mathrm{m}$ collapse (Figs. 8 and 9). As emphasized in the Results, AGE induces MPT that, however, seems to exhibit a different mechanism with respect to the well-known one (48). In fact, on the basis of the reported results, this mechanism, as mentioned above, seems to not be dependent on exogenous supraphysiological $\mathrm{Ca}^{2+}$ concentrations, while the involvement of an oxidative stress is strongly in doubt, due to the apparent scarce effect of DTE and spermine (Fig. 11). To provide a possible explanation for these observations, a previous theory on MPT proposed by Halestrap and Davidson (71) should be considered. These authors suggested that, in particular conditions, the adenine nucleotide translocase (AdNT), generally considered as the main protein on which the transition pore is open, can be transformed in a $\mathrm{K}^{+}$channel that, in turn, forms the aspecific transition pore leading to MPT. Thus, the effect of AGE, besides activating the $\mathrm{K}^{+} / \mathrm{H}^{+}$exchanger, could be that of transforming AdNT in the transition pore. The Halestrap-Davidson theory predicted that the transformation of AdNT in the $\mathrm{K}^{+}$channel and, subsequently, in the transition pore, needed the presence of phosphate and $\mathrm{Ca}^{2+}$. In this regard, it is worth noting that phosphate is present in the incubation medium, while $\mathrm{Ca}^{2+}$ is absent. Thus, the effect of AGE in altering the architecture of the membrane, by acting on the $\mathrm{K}^{+} / \mathrm{H}^{+}$exchanger, should be responsible for transforming AdNT in a $\mathrm{K}^{+}$channel. Then, AGE should be able to induce the binding of endogenous $\mathrm{Ca}^{2+}$ to the critical site(s) located on AdNT and responsible of transforming $\mathrm{K}^{+}$channel in the aspecific pore without involving an oxidative stress (70). Thus, it can be emphasized that AGE induces MPT by involving only endogenous $\mathrm{Ca}^{2+}$. In this regard, it should be considered that endogenous $\mathrm{Ca}^{2+}$, in the presence of phosphate, cycles across the mitochondrial membranes and, most probably, AGE causes the interaction of the cation with the critical site(s) responsible of MPT induction (71). The presence of RR, that blocks the uptake of $\mathrm{Ca}^{2+}$ during its cycling, prevents the cation binding to the above mentioned site(s) and consequently prevents MPT induction.

The oxidizing effect exhibited by AGE in the mitochondria seems to be very surprising, as the compound generally exerts antioxidant and ROS-scavenging effects $(17,19)$. However, an explanation for this may be that AGE functions as a redox cycler in the mitochondria, similarly to several polyphenols and triterpene compounds, exhibiting both antioxidizing and oxidizing properties (72,73 and refs. therein). These opposite effects are generally observed in the mitochondria, since the respiratory chain contains iron-sulfur proteins that are involved in the above-mentioned mechanism coupled to the redox cyclers. Of note, it should be emphasized that the oxidative processes of AGE should not be considered as damage, but rather that they can contribute to the balance of both SH/SS and GSH/GSSG pools that are essential for mitochondrial physiology.

In conclusion, this study demonstrates that AGE is able to induce the phenomenon of MPT without the strong involvement of oxidative stress, even though the compound is able to cause it. Most probably, the contribution of the oxidizing effect of AGE in inducing MPT is negligible. Consequently, as it is well known, MPT is related to the release of pro-apoptotic factors, such as cytochrome $c$, apoptosis-inducing factor and Smac/Diablo, inducing cell death by intrinsic apoptosis (50).

\section{Acknowledgements}

The authors would like to thank Dr Naoaki Morihara for reading the manuscript.

\section{Funding}

The authors would like to thank 'La Sapienza' University of Rome and Italian MIUR (Ministero dell'Istruzione, dell'Università e della Ricerca), AIRC IG 17575. EA would like to thank Wakunaga Pharmaceutical Co., Ltd. (Japan) for the scholarship given to $\mathrm{SO}$ and $\mathrm{YK}$ for supporting their $\mathrm{PhD}$ research and for supplying AGE. EA would also like to thank the Fondazione 'Enrico ed Enrica Sovena'. LDV is grateful to the financial support provided by Dipartimento di Scienze del Farmaco-Università di Padova-Progetti di Ricerca di Dipartimento PRID 2017.

\section{Availability of data and materials}

The datasets used and/or analyzed during the current study are available from the corresponding author on reasonable request.

\section{Authors' contributions}

AT and EA conceived this investigation and co-ordinated the collaboration among the authors. SO and YK performed all the experiments on human cancer cells. LDV and ANGA carried out the flow cytometric analysis on HeLa and A2780 cells. SG carried out the experiments on isolated rat liver mitochondria. PA and GC provided the AGS cells for the experiments and optimized the protocols for flow cytometric analyses, respectively. All authors wrote the manuscript and all authors have read and approved the final manuscript.

\section{Ethics approval and consent to participate}

The animal experimental procedures were approved by the local Ethics Committee for Animal Experimentation (CEASA) (protocol no. 3619, 15.1.2014) and performed in agreement with the international guidelines as well as European Communities Council Directive and National Regulations (CEE Council 86/609 and DL 116/92).

\section{Patient consent for publication}

Not applicable.

\section{Competing interests}

The authors declare that they have no competing interests.

\section{References}

1. Gallo M, Altieri F, Di Stadio CS, Miselli G, Villano V, Arcari P and Rippa E: An overview on factors underlying gastric cancer; strategies for its management with particular reference to diet. J Gastrointest Dig Syst 6: 399-408, 2016. 
2. Fleischauer AT, Poole C and Arab L: Garlic consumption and cancer prevention: Meta-analyses of colorectal and stomach cancers. Am J Clin Nutr 72: 1047-1052, 2000.

3. Rahman K and Lowe GM: Garlic and cardiovascular disease: A critical review. J Nutr 136 (Suppl 3): 736S-740S, 2006.

4. Banerjee SK and Maulik SK: Effect of garlic on cardiovascular disorders: A review. Nutr J 1: 4, 2002.

5. Chu Q, Ling MT, Feng H, Cheung HW, Tsao SW, Wang X and Wong YC: A novel anticancer effect of garlic derivatives: Inhibition of cancer cell invasion through restoration of E-cadherin expression. Carcinogenesis 27: 2180-2189, 2006.

6. Thomson M and Ali M: Garlic [Allium sativum]: A review of its potential use as an anti-cancer agent. Curr Cancer Drug Targets 3 : 67-81, 2003.

7. Li G, Qiao C, Lin R, Pinto J, Osborne M and Tiwari R: Antiproliferative effects of garlic constituents in cultured human breast-cancer cells. Oncol Rep 2: 787-791, 1995.

8. Shirin H, Pinto JT, Kawabata Y, Soh JW, Delohery T, Moss SF, Murty V, Rivlin RS, Holt PR and Weinstein IB: Antiproliferative effects of $S$-allylmercaptocysteine on colon cancer cells when tested alone or in combination with sulindac sulfide. Cancer Res 61: 725-731, 2001

9. Hosono T, Fukao T, Ogihara J, Ito Y, Shiba H, Seki T and Ariga T: Diallyl trisulfide suppresses the proliferation and induces apoptosis of human colon cancer cells through oxidative modification of beta-tubulin. J Biol Chem 280: 41487-41493, 2005.

10. Howard EW, Ling MT, Chua CW, Cheung HW, Wang $X$ and Wong YC: Garlic-derived $S$-allylmercaptocysteine is a novel in vivo antimetastatic agent for androgen-independent prostate cancer. Clin Cancer Res 13: 1847-1856, 2007.

11. Sriram N, Kalayarasan S, Ashokkumar P, Sureshkumar A and Sudhandiran G: Diallyl sulfide induces apoptosis in Colo 320 DM human colon cancer cells: Involvement of caspase-3, NF-kappaB and ERK-2. Mol Cell Biochem 311: 157-165, 2008.

12. Lai KC, Kuo CL, Ho HC, Yang JS, Ma CY, Lu HF, Huang HY, Chueh FS, Yu CC and Chung JG: Diallyl sulfide, diallyl disulfide and diallyl trisulfide affect drug resistant gene expression in colo 205 human colon cancer cells in vitro and in vivo. Phytomedicine 19: 625-630, 2012

13. Yan JY, Tian FM, Hu WN, Zhang JH, Cai HF and Li N: Apoptosis of human gastric cancer cells line SGC 7901 induced by garlicderived compound $S$-allylmercaptocysteine (SAMC). Eur Rev Med Pharmacol Sci 17: 745-751, 2013.

14. Zhang H, Wang K, Lin G and Zhao Z: Antitumor mechanisms of $S$-allyl mercaptocysteine for breast cancer therapy. BMC Complement Altern Med 14: 270, 2014.

15. Kodera Y, Ushijima M, Amano H, Suzuki JI and Matsutomo T: Chemical and biological properties of S-1-propenyl-1-cysteine in aged garlic extract. Molecules 22: E570, 2017.

16. Franco-Enzástiga Ú, Santana-Martínez RA, Silva-Islas CA, Barrera-Oviedo D, Chánez-Cárdenas ME and Maldonado PD Chronic administration of $S$-allylcysteine activates $\mathrm{Nrf2}$ factor and enhances the activity of antioxidant enzymes in the striatum, frontal cortex and hippocampus. Neurochem Res 42: 3041-3051, 2017.

17. Imai J, Ide N, Nagae S, Moriguchi T, Matsuura H and Itakura $Y$ : Antioxidant and radical scavenging effects of aged garlic extract and its constituents. Planta Med 60: 417-420, 1994.

18. Wei Z and Lau BHS: Garlic inhibits free radical generation and augments antioxidant enzyme activity in vascular endothelial cells. Nutr Res 18: 61-70, 1998.

19. Borek C: Antioxidant health effects of aged garlic extract. J Nutr 131: 1010S-1015S, 2001

20. Tanaka S, Haruma K, Kunihiro M, Nagata S, Kitadai Y, Manabe N, Sumii M, Yoshihara M, Kajiyama G and Chayama K: Effects of aged garlic extract (AGE) on colorectal adenomas: A double-blinded study. Hiroshima J Med Sci 53: 39-45, 2004

21. Matsuura N, Miyamae Y, Yamane K, Nagao Y, Hamada Y, Kawaguchi N, Katsuki T, Hirata K, Sumi S and Ishikawa H: Aged garlic extract inhibits angiogenesis and proliferation of colorectal carcinoma cells. J Nutr 136 (Suppl 3): 842S-846S 2006

22. Budoff MJ, Takasu J, Flores FR, Niihara Y, Lu B, Lau BH, Rosen RT and Amagase $\mathrm{H}$ : Inhibiting progression of coronary calcification using Aged Garlic Extract in patients receiving statin therapy: A preliminary study. Prev Med 39: 985-991, 2004

23. Morihara N, Hino A, Yamaguchi T and Suzuki J: Aged garlic extract suppresses the development of atherosclerosis in apolipoprotein E-knockout mice. J Nutr 146: 460S-463S, 2016.
24. Ried K, Travica N and Sali A: The effect of aged garlic extract on blood pressure and other cardiovascular risk factors in uncontrolled hypertensives: The AGE at Heart trial. Integr Blood Press Control 9: 9-21, 2016.

25. Thorajak P, Pannangrong W, Welbat JU, Chaijaroonkhanarak W, Sripanidkulchai K and Sripanidkulchai B: Effects of Aged Garlic Extract on cholinergic, glutamatergic and GABAergic systems with regard to cognitive impairment in $\mathrm{A} \beta$-induced rats. Nutrients 9: 686-698, 2017

26. Morihara N, Hino A, Miki S, Takashima M and Suzuki JI: Aged garlic extract suppresses inflammation in apolipoprotein E-knockout mice. Mol Nutr Food Res 61: 10-16, 2017.

27. Zeinali H, Baluchnejadmojarad T, Fallah S, Sedighi M, Moradi N and Roghani M: $S$-allyl cysteine improves clinical and neuropathological features of experimental autoimmune encephalomyelitis in C57BL/6 mice. Biomed Pharmacother 97: 557-563, 2018.

28. Katsuki T, Hirata K, Ishikawa H, Matsuura N, Sumi S and Itoh H: Aged garlic extract has chemopreventative effects on 1,2-dimethylhydrazine-induced colon tumors in rats. J Nutr 136 (Suppl 3): 847S-851S, 2006

29. Jikihara H, Qi G, Nozoe K, Hirokawa M, Sato H, Sugihara Y and Shimamoto F: Aged garlic extract inhibits 1,2-dimethylhydrazine-induced colon tumor development by suppressing cell proliferation. Oncol Rep 33: 1131-1140, 2015

30. Amagase H: Clarifying the real bioactive constituents of garlic. J Nutr 136 (Suppl 3): 716S-725S, 2006.

31. Matsutomo T and Kodera Y: Development of an analytic method for sulfur compounds in aged garlic extract with the use of a postcolumn high performance liquid chromatography method with sulfur-specific detection. J Nutr 146: 450S-455S, 2016.

32. Leanza L, Zoratti M, Gulbins E and Szabo I: Mitochondrial ion channels as oncological targets. Oncogene 33: 5569-5581, 2014.

33. Kyo E, Uda N, Kasuga S and Itakura Y: Immunomodulatory effects of aged garlic extract. J Nutr 131: 1075S-1079S, 2001.

34. Morihara N, Sumioka I, Moriguchi T, Uda N and Kyo E: Aged garlic extract enhances production of nitric oxide. Life Sci 71: 509-517, 2002.

35. Grandi M, Geroni $\mathrm{C}$ and Giuliani FC: Isolation and characterization of a human colon adenocarcinoma cell line resistant to doxorubicin. Br J Cancer 54: 515-518, 1986.

36. Agostinelli E, Belli F, Molinari A, Condello M, Palmigiani P, Vedova LD, Marra M, Seiler N and Arancia G: Toxicity of enzymatic oxidation products of spermine to human melanoma cells (M14): Sensitization by heat and MDL 72527. Biochim Biophys Acta 1763: 1040-1050, 2006.

37. Molinari A, Toccacieli L, Calcabrini A, Diociaiuti M, Cianfriglia $M$ and Arancia G: Induction of P-glycoprotein expression on the plasma membrane of human melanoma cells. Anticancer Res 20: 2691-2696, 2000.

38. Dolfini E, Dasdia T, Arancia G, Molinari A, Calcabrini A, Scheper RJ, Flens MJ, Gariboldi MB and Monti E: Characterization of a clonal human colon adenocarcinoma line intrinsically resistant to doxorubicin. Br J Cancer 76: 67-76, 1997.

39. Agostinelli E, Condello M, Molinari A, Tempera G, Viceconte N and Arancia G: Cytotoxicity of spermine oxidation products to multidrug resistant melanoma M14 ADR2 cells: Sensitization by the MDL 72527 lysosomotropic compound. Int J Oncol 35: 485-498, 2009

40. Frezza C, Cipolat S and Scorrano L: Organelle isolation: Functional mitochondria from mouse liver, muscle and cultured fibroblasts. Nat Protoc 2: 287-295, 2007.

41. Gornall AG, Bardawill CJ and David MM: Determination of serum proteins by means of the biuret reaction. J Biol Chem 177 : 751-766, 1949.

42. Kamo N, Muratsugu M, Hongoh R and Kobatake Y: Membrane potential of mitochondria measured with an electrode sensitive to tetraphenyl phosphonium and relationship between proton electrochemical potential and phosphorylation potential in steady state. J Membr Biol 49: 105-121, 1979.

43. Santos AC, Uyemura SA, Lopes JLC, Bazon JN, Mingatto FE and Curti C: Effect of naturally occurring flavonoids on lipid peroxidation and membrane permeability transition in mitochondria. Free Radic Biol Med 24: 1455-1461, 1998.

44. Crompton M and Costi A: Kinetic evidence for a heart mitochondrial pore activated by $\mathrm{Ca}^{2+}$, inorganic phosphate and oxidative stress. A potential mechanism for mitochondrial dysfunction during cellular $\mathrm{Ca}^{2+}$ overload. Eur J Biochem 178: 489-501, 1988.

45. Toninello A, Miotto G, Siliprandi D, Siliprandi N and Garlid KD: On the mechanism of spermine transport in liver mitochondria. J Biol Chem 263: 19407-19411, 1988. 
46. Managò A,Leanza L, Carraretto L, Sassi N, Grancara S, QuintanaCabrera R, Trimarco V, Toninello A, Scorrano L, Trentin L, et al: Early effects of the antineoplastic agent salinomycin on mitochondrial function. Cell Death Dis 6: e1930, 2015.

47. Mitchell P and Moyle J: Estimation of membrane potential and $\mathrm{pH}$ difference across the cristae membrane of rat liver mitochondria. Eur J Biochem 7: 471-484, 1969.

48. Nakashima RA and Garlid KD: Quinine inhibition of $\mathrm{Na}^{+}$and $\mathrm{K}^{+}$ transport provides evidence for two cation $/ \mathrm{H}^{+}$exchangers in rat liver mitochondria. J Biol Chem 257: 9252-9254, 1982.

49. Zoratti M and Szabò I: The mitochondrial permeability transition. Biochim Biophys Acta 1241: 139-176, 1995.

50. Susin SA, Zamzami N and Kroemer G: Mitochondria as regulators of apoptosis: Doubt no more. Biochim Biophys Acta 1366: 151-165, 1998.

51. Agostinelli E, Belli F, Dalla Vedova L, Marra M, Crateri P and Arancia G: Hyperthermia enhances cytotoxicity of amine oxidase and spermine on drug-resistant LoVo colon adenocarcinoma cells. Int J Oncol 28: 1543-1553, 2006.

52. Takahashi T, Horie H, Kojima O and Itoh M: Preoperative combined treatment with radiation, intraluminal hyperthermia, and 5-fluorouracil suppositories for patients with rectal cancer. Surg Today 23: 1043-1048, 1993.

53. Vernon CC, Hand JW, Field SB, Machin D, Whaley JB, van der Zee J, van Putten WL, van Rhoon GC, van Dijk JD, González González D, et al; International Collaborative Hyperthermia Group: Radiotherapy with or without hyperthermia in the treatment of superficial localized breast cancer: Results from five randomized controlled trials. Int J Radiat Oncol Biol Phys 35: 731-744, 1996.

54. Bates DA and Mackillop WJ: The effect of hyperthermia in combination with melphalan on drug-sensitive and drug-resistant CHO cells in vitro. Br J Cancer 62: 183-188, 1990.

55. Dahl O: Mechanisms of thermal enhancement of chemotherapeutic cytotoxicity. In: Hyperthermia and Oncology. Urano M and Douple E (eds). Vol 4. Utrecht, VSP, pp9-28, 1994.

56. Reinhold HS and Endrich B: Tumour microcirculation as a target for hyperthermia. Int J Hyperthermia 2: 111-137, 1986.

57. Agostinelli E, Arancia G, Calcabrini A, Matarrese $\mathrm{P}$, Mondovì $\mathrm{B}$ and Pietrangeli P: Hyperthermia-induced biochemical and ultrastructural modifications in cultured cells. Exp Oncol 17: 269-276, 1995.

58. Maeda H, Seymour LW and Miyamoto Y: Conjugates of anticancer agents and polymers: Advantages of macromolecular therapeutics in vivo. Bioconjug Chem 3: 351-362, 1992.

59. Demers N, Agostinelli E, Averill-Bates DA and Fortier G: Immobilization of native and poly(ethylene glycol)-treated ('PEGylated') bovine serum amine oxidase into a biocompatible hydrogel. Biotechnol Appl Biochem 33: 201-207, 2001.

60. Cheng Z, Al Zaki A, Hui JZ, Muzykantov VR and Tsourkas A Multifunctional nanoparticles: Cost versus benefit of adding targeting and imaging capabilities. Science 338: 903-910, 2012.

61. Bertrand N, Wu J, Xu X, Kamaly N and Farokhzad OC: Cancer nanotechnology: The impact of passive and active targeting in the era of modern cancer biology. Adv Drug Deliv Rev 66: 2-25, 2014.
62. Agostinelli E, Vianello F, Magliulo G, Thomas T and Thomas TJ: Nanoparticle strategies for cancer therapeutics: Nucleic acids, polyamines, bovine serum amine oxidase and iron oxide nanoparticles (Review). Int J Oncol 46: 5-16, 2015.

63. Venditti I, Hassanein TF, Fratoddi I, Fontana L, Battocchio C, Rinaldi F, Carafa M, Marianecci C, Diociaiuti M, Agostinelli E, et al: Bioconjugation of gold-polymer core-shell nanoparticles with bovine serum amine oxidase for biomedical applications. Colloids Surf B Biointerfaces 134: 314-321, 2015.

64. Montanari E, Capece S, Di Meo C, Meringolo M, Coviello T, Agostinelli E and Matricardi P: Hyaluronic acid nanohydrogels as a useful tool for BSAO immobilization in the treatment of melanoma cancer cells. Macromol Biosci 13: 1185-1194, 2013.

65. Sinigaglia G, Magro M, Miotto G, Cardillo S, Agostinelli E, Zboril R, Bidollari E and Vianello F: Catalytically active bovine serum amine oxidase bound to fluorescent and magnetically drivable nanoparticles. Int J Nanomedicine 7: 2249-2259, 2012.

66. Garlid KD, Dos Santos P, Xie ZJ, Costa AD and Paucek P. Mitochondrial potassium transport: The role of the mitochondrial ATP-sensitive $\mathrm{K}(+)$ channel in cardiac function and cardioprotection. Biochim Biophys Acta 1606: 1-21, 2003.

67. Garlid KD and Paucek P: Mitochondrial potassium transport: The $\mathrm{K}(+)$ cycle. Biochim Biophys Acta 1606: 23-41, 2003.

68. Garlid KD: Opening mitochondrial K(ATP) in the heart - what happens, and what does not happen. Basic Res Cardiol 95: 275-279, 2000

69. Tian J, Liu J, Garlid KD, Shapiro JI and Xie Z: Involvement of mitogen-activated protein kinases and reactive oxygen species in the inotropic action of ouabain on cardiac myocytes. A potential role for mitochondrial K(ATP) channels. Mol Cell Biochem 242: 181-187, 2003.

70. Greenbaum NL and Wilson DF: The distribution of inorganic phosphate and malate between intra- and extramitochondrial spaces. Relationship with the transmembrane $\mathrm{pH}$ difference. J Biol Chem 260: 873-879, 1985.

71. Halestrap AP and Davidson AM: Inhibition of Ca2(+)-induced large-amplitude swelling of liver and heart mitochondria by cyclosporin is probably caused by the inhibitor binding to mitochondrial-matrix peptidyl-prolyl cis-trans isomerase and preventing it interacting with the adenine nucleotide translocase. Biochem J 268: 153-160, 1990.

72. Battaglia V, Brunati AM, Fiore C, Rossi CA, Salvi M, Tibaldi E, Palermo M, Armanini D and Toninello A: Glycyrrhetinic acid as inhibitor or amplifier of permeability transition in rat heart mitochondria. Biochim Biophys Acta 1778: 313-323, 2008.

73. Salvi M, Brunati AM, Clari G and Toninello A: Interaction of genistein with the mitochondrial electron transport chain results in opening of the membrane transition pore. Biochim Biophys Acta 1556: 187-196, 2002. 